\title{
Effect of perineal massage in the second stage of labour, on the incidence of episiotomy and perineal tears
}

\author{
Abinaya Raja, Pallavee P.*, Rupal Samal \\ Department of Obstetrics and Gynecology, Mahatma Gandhi Medical College and Research Institute, Sri Balaji \\ Vidyapeeth University, Puducherry, India
}

Received: 24 January 2019

Accepted: 05 March 2019

\section{*Correspondence:}

Dr. Pallavee P.,

E-mail: ppallavee@ rediffmail.com

Copyright: () the author(s), publisher and licensee Medip Academy. This is an open-access article distributed under the terms of the Creative Commons Attribution Non-Commercial License, which permits unrestricted non-commercial use, distribution, and reproduction in any medium, provided the original work is properly cited.

\section{ABSTRACT}

Background: This study aimed to investigate whether perineal massage during second stage of labour could decrease perineal trauma in the form of episiotomy and perineal tears.

Methods: One hundred and fifty term antenatal women in labour were randomly assigned to two groups, one of which received perineal massage and the other received routine care during the second stage. Frequency of episiotomies, perineal tears, intact perineums, degrees of perineal tears, duration of second stage of labour and perineal pain after 24 hours was compared.

Results: Perineal massage was efficient in reducing incidence of episiotomy, duration of second stage of labour and perineal pain assessed 24 hours after delivery. The frequency of perineal tears and intact perineums did not differ significantly. Perineal massage was protective against severe form of third degree perineal tears.

Conclusions: Authors suggest that perineal massage can be routinely practiced by health professionals to improve quality of life in women post vaginal delivery.

Keywords: Episiotomy, Intact perineum, Perineal massage, Perineal tear, Second stage labour

\section{INTRODUCTION}

Perineal trauma is defined as any damage to the genitalia during childbirth, either spontaneously or due to an episiotomy. ${ }^{1}$

Perineal damage may result in urinary and fecal incontinence, painful intercourse, persistent perineal pain, and weakness of pelvic floor musculature., ${ }^{2,3}$

Episiotomy is equivalent in its extent to a spontaneous second-degree perineal tear. Studies state that episiotomy guarantees perineal trauma. ${ }^{4}$ Thus, selective episiotomy and perineal protective techniques are recommended to decrease maternal morbidity. Perineal protective techniques like warm compress, hands off, hands on and perineal massage have been proposed to prevent perineal trauma during childbirth. ${ }^{5,6}$

Perineal massage stimulates both rehabilitation and the re-elasticization of tissues and muscles and is thought to have a positive effect on vaginal delivery owing to its impact on tissues and muscles in the perineal area.

Perineal massage can prevent perineal tear, protect perineal integrity, reduce postpartum perineal pain and enable women to rapidly regain pelvic floor muscle function after delivery. ${ }^{7}$

The purpose of the present study was to assess the effect of perineal massage during the second stage of labour on the incidence of episiotomy and perineal tears. 


\section{METHODS}

\section{Inclusion criteria}

- All term primigravida with a singleton live fetus, fulfilling vaginal delivery requirements, with cephalic presentation and no medical complications, admitted for delivery in the labour ward of the Department of Obstetrics and Gynaecology at Mahatma Gandhi Medical College and Research Institute, Pondicherry from March 2016 to April 2017, were enrolled in the study, after getting written informed consent from the participants.

\section{Exclusion criteria}

- Patients with multiple gestation, previous scarred perineum, narrowed pelvis or macrosomia, vaginal infection, patients undergoing emergency lower segment caearean section (LSCS) or labour under epidural analgesia were excluded.

\section{Procedure}

The study was conducted after obtaining clearance from the ethical committee of the Institute. Participants at the beginning of the second stage of labour were randomly assigned, with the help of a computer-generated random number table, to the perineal massage or the control group. The second stage of labour was diagnosed with onset of full dilatation of cervix. Blinding could not be done due to the nature of intervention.

Perineal massage was administered to all women in the massage group during the second stage of labour, by the primary investigator. Before the massage was started, it was ensured that the urinary bladder was empty. In the second stage of labour, each patient was taken to the labour board and received perineal massage in the lithotomy position. Perineal massage was given with $2 \%$ lignocaine gel, gently, using two fingers of the gloved hand (index and middle) inside the vagina and thumb over the perineum in a sweeping motion. Mild downward pressure (toward the rectum) was applied with steady, lateral strokes which lasted one second in each direction. Perineal massage was given very gently during uterine contraction, to reduce the discomfort to the participant. Routine care was administered by the primary investigator, to all the women in control group, with perineal support using a vulval pad. In both the groups, medio-lateral episiotomy was given in case of impending perineal tear, fetal distress, or requirement of instrumental delivery.

It was decided to exclude patients who would undergo caesarean section in second stage of labour or have instrumental delivery from analysis. The CONSORT flow chart for the study is shown in Figure 1.

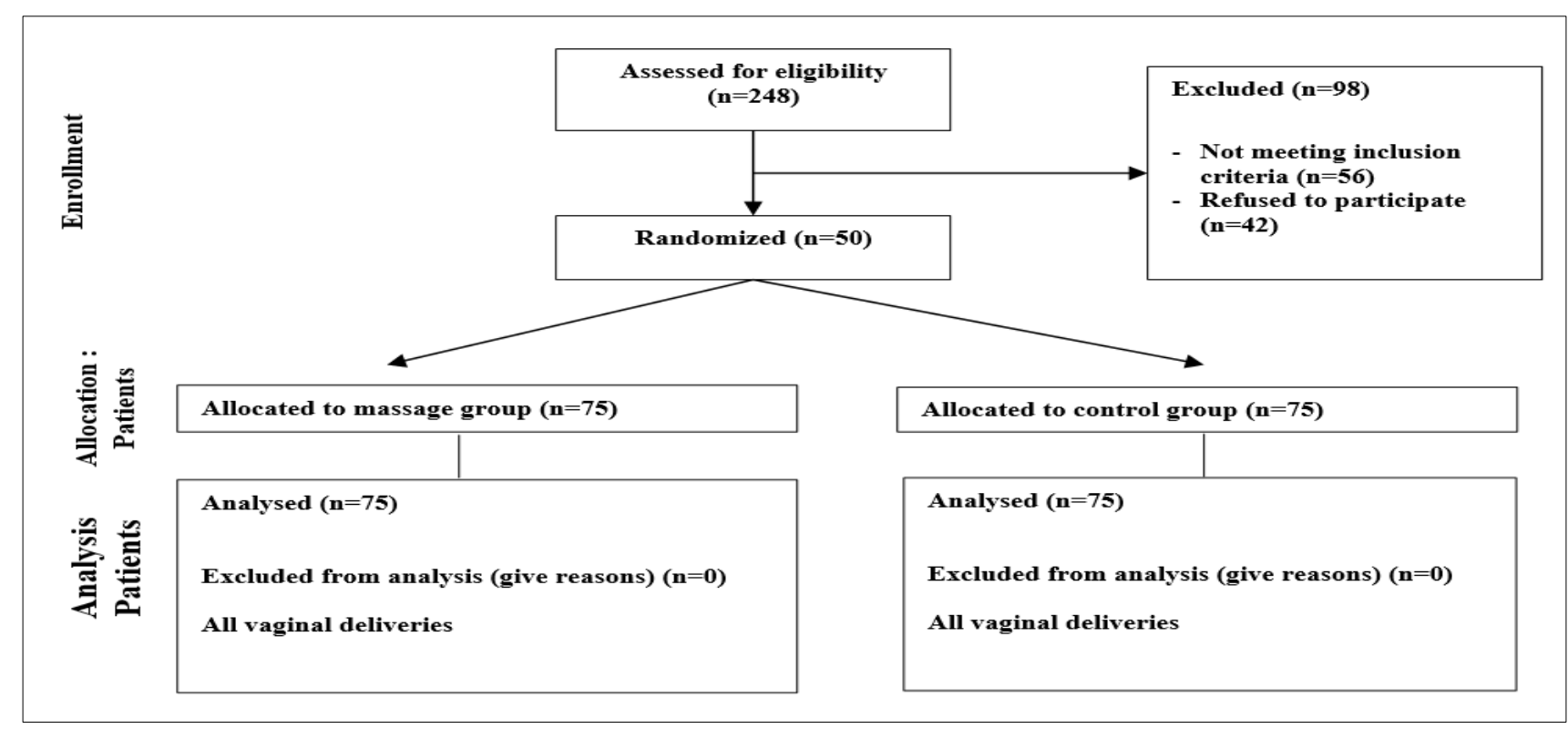

Figure 1: CONSORT flow chart.

After the expulsion of placenta and membranes, a systematic examination was done to look for the presence of any genital tract tears. Perineal outcome was measured in terms of incidence of episiotomy and perineal tears, type of perineal tears and intact perineum. An intact perineum was described as a vagina or vulva that did not need any repairs or have any perineal tear. 
Perineal tear was classified on the basis of Sultan's classification, as follows: ${ }^{8}$

- First-degree tear-Injury to perineal skin and / or vaginal mucosa

- Second-degree tear-Injury to perineum involving perineal muscles but not involving the anal sphincter

- Third-degree tear-Injury to perineum involving the anal sphincter complex

- Grade 3a tear- less than $50 \%$ of external anal sphincter (EAS) thickness torn

- Grade 3b tear- more than $50 \%$ of EAS thickness torn

- Grade 3c tear- both EAS and internal anal sphincter (IAS) torn

- Fourth-degree tear- injury to perineum involving anal sphincter complex (EAS + IAS) and anorectal mucosa

Neonatal details such as birth weight, Apgar score at 1 and 5 minutes and NICU admission were recorded. Study participants were followed up in the postpartum period, to assess pain in the perineum after 24 hours of delivery by using a numeric rating scale. The patient was asked to circle a number between 0 and 10 that aptly described her pain intensity.

\section{Statistical analysis}

The proportion of perineal trauma was $73 \%$ among the massage group in a previous study (Geranmayeh 2012), and a $23 \%$ increase was recorded in the control group, with the proportion $96 \%$. Assuming an $\alpha$ error of 0.05 and with a power of $80 \%$, the sample size was estimated to 66 . With probability of $10 \%$ drop out of cases, the minimum sample size was estimated to be 72 . Authors chose 75 patients in each group. The clinical data were prospectively obtained and entered into SPSS Windows version 22.0. Categorical variables have been reported as percentages and compared using the Chi-square test or the Fisher's exact test, as appropriate, whereas continuous variables were analyzed using the student t-test or MannWhitney U-test, as appropriate. Statistical significance was set at $\mathrm{P}<0.05$.

\section{RESULTS}

One hundred fifty term antenatal women in labour were randomly assigned to two groups, one of 75 , receiving perineal massage and the other group of 75 receiving routine care during the second stage of labour. The baseline characteristics of both massage and control group were similar (Table 1). All the participants in both the groups delivered vaginally.

The incidence of episiotomy was significantly higher $(p=0.016)$ in the control group $(93.3 \%)$ than in the massage group (80\%) as shown in Table 2 . The incidence of perineal tears in the massage group $(16 \%)$ and control group $(9.4 \%)$ were similar ( $\mathrm{p}=0,22$; Table 2$)$. Among the study participants in massage group, $6.7 \%$ had first degree perineal tear, $9.3 \%$ had second degree and no participant had third or fourth degree perineal tear (Table 2).

Table 1: Comparison of baseline characteristics among massage and control group.

\begin{tabular}{|l|l|l|l|l|}
\hline Characteristic & Massage group $(\mathbf{N}=75)$ & Control group $(\mathbf{N}=75)$ & t statistic & p-value \\
\hline Age (year) & $24.68 \pm 2.89$ & $24.80 \pm 3.41$ & 0.232 & 0.817 \\
\hline Gestational age (week) & $38.6 \pm 1$ & $38.6 \pm 1$ & 0.071 & 0.943 \\
\hline BMI $\left(\mathrm{kg} / \mathrm{m}^{2}\right)$ & $24 \pm 3.22$ & $24.25 \pm 2.92$ & 0.499 & 0.618 \\
\hline
\end{tabular}

BMI: Body Mass Index

Table 2: Incidence of episiotomies, perineal tears and intact perineums between the two groups.

\begin{tabular}{|l|l|l|l|l|l|}
\hline Types of perineal tear & Massage group N $\mathbf{~ 7 5}$ & \multicolumn{2}{c|}{ Control group N $=75$} & p-values \\
\hline Episiotomy & $\mathbf{N}$ & $\mathbf{\%}$ & $\mathbf{N}$ & $\mathbf{\%}$ & $0.016^{*}$ \\
\hline Perineal tear & 60 & 80 & 70 & 93.3 & 0.22 \\
\hline First degree & 12 & 16 & 7 & 9.4 & 0.096 \\
\hline Second degree & 5 & 6.7 & 1 & 1.3 & 0.19 \\
\hline Third degree & 7 & 9.3 & 3 & 4 & 0.08 \\
\hline Fourth degree & 0 & 0 & 3 & 4 & - \\
\hline Intact perineum & 0 & 0 & 0 & 0 & 0.08 \\
\hline
\end{tabular}

$* \mathrm{P}<0.05$

In the control group $1.3 \%$ had first degree perineal tear, $4 \%$ had second degree, $4 \%$ third degree perineal tear and no participant had fourth degree perineal tear. There was no significant difference in distribution of perineal tears 
between the two groups. The incidence of intact perineum in the massage group (4\%) was not significantly different $(\mathrm{p}=0.08)$ from those in the control group $(n=0)$.

The event rate of episiotomy was 0.933 in the control group and 0.8 in the massage group. The risk of getting an episiotomy in the massage group was 0.874 times less than in the control group (Table 3). Risk difference between groups for episiotomy was 0.133 . The event rate of perineal tear was 0.093 in the control group and 0.16 in the massage group (Table 3). The risk of getting a perineal tear was 1.7 times more in the massage group than in controls. Risk difference for perineal tear was 0.066. Thus, for preventing episiotomy, by offering perineal massage, the numbers needed to treat (NNT) would be 7.6 , while, for preventing perineal tears, the NNT would be 15.1 .

Table 3: Risk assessment of episiotomy and perineal tear.

\begin{tabular}{|l|l|l|l|l|l|}
\hline & Incidence & $\begin{array}{l}\text { Absolute } \\
\text { risk (I) }\end{array}$ & $\begin{array}{l}\text { Episiotomy } \\
\text { Relative risk } \\
\text { (Im/Ic) }\end{array}$ & $\begin{array}{l}\text { Absolute risk } \\
\text { reduction (Ic-Im) }\end{array}$ & $\begin{array}{l}\text { Number needed to } \\
\text { treat (100/ARR) }\end{array}$ \\
\hline Massage group (75) & 60 & 0.8 & 0.874 & 0.133 & 7.6 \\
\hline Control group (75) & 70 & 0.933 & Perineal tear & & \\
\hline & Incidence & $\begin{array}{l}\text { Absolute } \\
\text { risk (I) }\end{array}$ & $\begin{array}{l}\text { Relative risk } \\
\text { (Im/Ic) }\end{array}$ & $\begin{array}{l}\text { Absolute risk } \\
\text { reduction (Ic-Im) }\end{array}$ & $\begin{array}{l}\text { Number needed to } \\
\text { treat (100/ARR) }\end{array}$ \\
\hline Massage group (75) & 12 & 0.16 & 1.714 & 0.066 & 15.1 \\
\hline Control group (75) & 7 & 0.093 & & & \\
\hline
\end{tabular}

Im: Incidence in massage group; Ic: Incidence in control group; ARR: Absolute Risk Reduction

The mean duration of second stage of labour in the massage group $(42.13 \pm 14.19$ mins $)$ was significantly shorter than in the control group ( $51.45 \pm 14.45$ mins). The mean pain score in the massage group $(4.15 \pm 0.93)$ was significantly less $(\mathrm{p}=0.038)$ than in the control group $(4.47 \pm 0.95)$. There was no significant difference $(\mathrm{p}=0.666)$ in the mean birth weights of the neonates in the massage group $(2940 \pm 343 \mathrm{~g})$ and in the control group $(2916 \pm 344 \mathrm{~g})$. The mean APGAR score at 1 minute in the massage and control groups were 7.77 \pm 0.56 and $7.65 \pm 0.73$ respectively. Similarly, the mean APGAR scores at 5 minutes in the massage and control groups were $8.97 \pm 0.16$ and $8.95 \pm 0.28$ respectively. There was no significant difference in APGAR scores at 1 minute $[p=0.259]$ and 5 minutes $(p=0.476)$ between the two groups. There were no neonates in either group with Apgar less than 7 at 5 minutes. Twenty per cent of the neonates had Neonatal Intensive Care Unit (NICU) admission in either group.

\section{DISCUSSION}

Present study results suggest that perineal massage reduced incidence of episiotomy but with no effect on perineal tears. The duration of second stage of labour and the perineal pain 24 hours after delivery were also significantly reduced following perineal massage.

In the present study, the incidence of episiotomy in the massage group was $80 \%$ and in the control group it was $93 \%$, which might be deemed high. Karacam et al, too had high rates of episiotomy in both their massage and control group (52\% and $60 \%$ respectively). ${ }^{9}$ This high incidence rate of episiotomy in present group could be explained due to the fact that, previously routine episiotomy for primigravida was practiced in present institution, which might have been an influencing factor for higher incidence rate of episiotomy, due to increased fear of impending perineal tear. As opposed to this, the incidence rate of episiotomy in the study conducted by Stamp et al, was $24 \%$ in the massage group and $26 \%$ in the control group, but their results may not be comparable with ours, as it included both primi and multigravida. ${ }^{10}$ Though authors had high rates of episiotomy in both the groups, present results showed that perineal massage had an effect on reducing the incidence of episiotomy significantly, by about $13 \%$ (Relative Risk-0.874, P value-0.016).

This was similar to other studies which showed a reduced incidence of episiotomy by $13 \% .^{9}$ Zare et al, reported a decrease in episiotomy rate by $5 \%$, which was not statistically significant. ${ }^{11}$ Similarly, there was no significant difference in rates of episiotomy in studies which included both primigravida and multiparous women. ${ }^{10,12}$

In present study the relative risk of episiotomy was 0.874 with $95 \%$ CI of 0.74 to 0.97 . Thus, the risk of episiotomy was 0.874 times less in the massage group than in the control group. Karacam et al, also show a risk reduction of episiotomy by 0.71 times in the massage group compared to the control group. ${ }^{9}$ However, Stamp et al, did a sub-analysis by parity and found no difference in 
the number of episiotomies in multiparous women. ${ }^{10}$ The NNT for avoiding an episiotomy therefore was 7.6 for patients receiving perineal massage.

Perineal massage had no effect on perineal tears but seemed to be protective against severe third and fourth degree perineal tear. The incidence of perineal tear in massage group was $16 \%$ and in the control group it was $9.4 \%$, but this difference was not found to be significant. Other authors have also reported high rates of spontaneous laceration in massage and control groups, although the difference in those groups were also not statistically significant. ${ }^{2,9,10,12}$ Hastings-Tolsma et al, reported that in lithotomy position when oils and lubricants were used, rate of tears were more. ${ }^{13}$ Perineal trauma can be associated with mother's position during labour, use of oxytocin, pushing effect and neonatal weight. Use of lithotomy position for childbirth and use of oxytocin in second stage labour may account for increased tears in present study.

In present study, the relative risk of perineal tear was 1.714 with $95 \%$ CI Of 0.71 to 4.11 , although on direct comparison between the two groups, the difference in incidence was not found to be statistically significant, as stated above. However, other authors have reported a trend towards reduced risk of third degree perineal tear in massage group (Relative risk-0.47, p-0.004). ${ }^{10}$ The only fourth degree perineal tear in their study was in the control group. Karacam et al, had high rates of spontaneous laceration in both groups but most of them were first degree, very few had second degree and none in both groups had severe forms of perineal tear. ${ }^{9}$ The calculated NNT for perineal massage to avoid a perineal tear was 15.1 .

In the present study, there was no significant difference in the incidence of women who had entirely intact perineums. Zare et al, delivered $22 \%$ of the primigravida in the massage group and $20 \%$ primigravida in control group with intact perineum. ${ }^{11}$ Thus, they observed that perineal massage with vaseline in the second stage of labour resulted in more intact perineums, with less episiotomies in the massage group than in the control group, as reflected in present study. Similar result was observed in other studies as well. ${ }^{10,12}$

Perineal tear has been associated with a prolonged second stage. None of the participants had prolongation of second stage of labour in present study. However, authors did find that there was significant reduction in the duration of second stage of labour in the massage group by up to 10 minutes. These findings correspond to the ones reported by other authors who have also observed that in the perineal massage group, the mean duration of second stage of labour was reduced substantially. ${ }^{10,14}$ The pain scores in patients after $24 \mathrm{hrs}$ of delivery were significantly reduced in the perineal massage group. Some authors have stated that perineal massage in the second stage decreased the pain in massage group after 3 days, 10 days and up to 3 months, but not significantly. ${ }^{10}$ However, others found no significant difference between groups with respect to perineal pain at 1 day, 3 weeks and 1 year after delivery. ${ }^{9}$

Birth outcomes like Apgar score and NICU admission were not found to be significantly different between both groups. Similar findings were seen in other studies..$^{9,10,12}$

Thus, due to varied results on different effects of perineal massage in the second stage of labour, further studies are required to evaluate its efficacy.

\section{CONCLUSION}

From the study authors conclude that perineal massage significantly reduces the incidence of episiotomy, duration of second stage of labour and perineal pain assessed 24 hours after delivery. However, it does not affect the frequency of perineal tears and intact perineum at the end of delivery. Despite this, it was protective against severe third and fourth degree perineal tear. In view of these findings, authors suggest that perineal massage can be routinely practiced by health professionals to improve quality of life in women post vaginal delivery.

\section{Funding: No funding sources}

Conflict of interest: None declared

Ethical approval: The study was approved by the Institutional Ethics Committee

\section{REFERENCES}

1. Kalichman L. Perineal massage to prevent perineal trauma in childbirth. Isr Med Assoc J. 2008;10:5313.

2. Mei-dan E, Walfisch A, Raz I, Levy A, Hallak M. Perineal massage during pregnancy: a prospective controlled trial. Isr Med Assoc J. 2008;10:499-502.

3. Eogan M, Daly L, O'Herlihy C. The effect of regular antenatal perineal massage on postnatal pain and anal sphincter injury: a prospective observational study. J Matern Fetal Neonatal Med. 2006;19:225-9.

4. Aasheim V, Nilsen AB, Lukasse M, Reinar LM. Perineal techniques during the second stage of labour for reducing perineal trauma. Cochrane Database Syst Rev. 2011;(12):CD006672.

5. Davidson K, Jacoby S, Brown MS. Prenatal perineal massage: preventing lacerations during delivery. J Obstet Gynecol Neonatal Nurs. 2000;29:474-9.

6. Johanson R. Perineal massage for prevention of perineal trauma in childbirth. Lancet. 2000;355:2501.

7. Demirel G, Golbasi Z. Effect of perineal massage on the rate of episiotomy and perineal tearing. Int $\mathrm{J}$ Gynaecol Obstet. 2015;131:183-6.

8. Sultan AH, Takar R. Lower genital tract and anal sphincter trauma. Best Pract Res Clin Obstet Gynaecol. 2002;16:99-116. 
9. Karaçam Z, Ekmen H, Calioir H. The use of perineal massage in the second stage of labour and follow-up of postpartum perineal outcomes. Health Care Women Int. 2012;33:697-718.

10. Stamp G, Kruzins G, Crowther C. Perineal massage in labour and prevention of perineal trauma: randomised controlled trial. BMJ. 2001;322:1277-80.

11. Zare O, Pasha H, Faramarzi M. Effect of perineal massage on the incidence of episiotomy and perineal laceration. Health. 2014;6:10.

12. Albers LL, Sedler KD, Bedrick EJ, Teaf D, Peralta P. Midwifery care measures in the second stage of labour and reduction of genital tract trauma at birth: a randomized trial. J Midwifery Womens Health. 2005;50:365-72.

13. Hastings-Tolsma M, Vincent D, Emeis C, Francisco $\mathrm{T}$. Getting through birth in one piece: protecting the perineum. MCN Am J Matern Child Nurs. 2007;32:158-64.

14. Geranmayeh M, Rezaei Habibabadi Z, Fallahkish B, Farahani MA, Khakbazan Z, Mehran A. Reducing perineal trauma through perineal massage with vaseline in second stage of labour. Arch Gynecol Obstet. 2012;285:77-81.

Cite this article as: Raja A, Pallavee P, Samal R. Effect of perineal massage in the second stage of labour, on the incidence of episiotomy and perineal tears. Int J Reprod Contracept Obstet Gynecol 2019;8:1387-92. 